\title{
Duration of total contact casting for resolution of acute Charcot foot: a retrospective cohort study
}

\author{
Danielle A. Griffiths ${ }^{1}$ and Michelle R. Kaminski ${ }^{2,3^{*}}$ (D)
}

\begin{abstract}
Background: Charcot neuroarthropathy (Charcot foot) is a highly destructive joint disease of the foot and ankle. If there is delayed diagnosis and treatment, it can lead to gross deformity, instability, recurrent ulceration and/or amputation. Total contact casting (TCC) is a treatment commonly used to immobilise the foot and ankle to prevent trauma, further destruction and preserve the foot structure during the inflammatory phase. At present, there is limited Australian data regarding the duration of TCC treatment for resolution of acute Charcot foot, and whether there are any patient and clinical factors affecting its duration. Therefore, this study aimed to address these deficiencies.

Methods: This study presents a retrospective analysis of 27 patients with acute Charcot foot attending for TCC treatment at a high-risk foot service (HRFS) in a large metropolitan health network in Melbourne, Australia. Over a three-year period, data were retrospectively collected by reviewing hospital medical records for clinical, demographic, medical imaging and foot examination information. To explore between-group differences, independent samples $t$ tests, Mann-Whitney $U$ tests, Chi-square tests, and/or Fisher's exact tests were calculated depending on data type. To evaluate associations between recorded variables and duration of TCC treatment, mean differences, odds ratios (OR) and $95 \%$ confidence intervals were calculated.
\end{abstract}

Results: Mean age was 57.9 (SD, 12.6) years, 66.7\% were male, 88.9\% had diabetes, 96.3\% had peripheral neuropathy, and $33.3 \%$ had peripheral arterial disease. Charcot misdiagnosis occurred in $63.0 \%$ of participants, and signs and symptoms consistent with acute Charcot foot were present for a median of 2.0 (IQR, 1.0 to 6.0) months prior to presenting or being referred to the HRFS. All participants had stage 1 Charcot foot. Of these, the majority were located in the tarsometatarsal joints (44.4\%) or midfoot (40.7\%) and were triggered by an ulcer or traumatic injury (85.2\%). The median TCC duration for resolution of acute Charcot foot was 4.3 (IQR, 2.7 to 7.8 ) months, with an overall complication rate of $5 \%$ per cast. Skin rubbing/irritation (40.7\%) and asymmetry pain (22.2\%) were the most common TCC complications. Osteoarthritis was significantly associated with a TCC duration of more than 4 months $(\mathrm{OR}, 6.00)$. Post TCC treatment, $48.1 \%$ returned to footwear with custom foot orthoses, $25.9 \%$ used a life-long Charcot Restraint Orthotic Walker, and 22.2\% had soft tissue or bone reconstructive surgery. There were no Charcot recurrences, however, contralateral Charcot occurred in 3 (11.1\%) participants.

(Continued on next page)

\footnotetext{
* Correspondence: m.kaminski@latrobe.edu.au

${ }^{2}$ Discipline of Podiatry, School of Allied Health, Human Services and Sport, La

Trobe University, Melbourne, Victoria 3086, Australia

${ }^{3}$ Department of Podiatry, St Vincent's Hospital Melbourne, Melbourne,

Victoria 3065, Australia

Full list of author information is available at the end of the article
}

\section{$\triangle B M C$}

(c) The Author(s). 2021 Open Access This article is licensed under a Creative Commons Attribution 4.0 International License, which permits use, sharing, adaptation, distribution and reproduction in any medium or format, as long as you give appropriate credit to the original author(s) and the source, provide a link to the Creative Commons licence, and indicate if changes were made. The images or other third party material in this article are included in the article's Creative Commons licence, unless indicated otherwise in a credit line to the material. If material is not included in the article's Creative Commons licence and your intended use is not permitted by statutory regulation or exceeds the permitted use, you will need to obtain permission directly from the copyright holder. To view a copy of this licence, visit http://creativecommons.org/licenses/by/4.0/ The Creative Commons Public Domain Dedication waiver (http://creativecommons.org/publicdomain/zero/1.0/) applies to the data made available in this article, unless otherwise stated in a credit line to the data. 
(Continued from previous page)

Conclusions: The median TCC duration for resolution of acute Charcot foot was 4 months, which is shorter or comparable to data reported in the United Kingdom, United States, Europe, and other Asia Pacific countries. Osteoarthritis was significantly associated with a longer TCC duration. The findings from this study may assist clinicians in providing patient education, managing expectations and improving adherence to TCC treatment for acute Charcot neuroarthropathy cases in Australia.

Keywords: Charcot foot, Diabetic foot, Foot deformities, Neurogenic arthropathy, Retrospective studies

\section{Background}

Charcot neuroarthropathy (Charcot foot) is a highly destructive joint disease characterised by progressive multiple bone fractures, dislocations and severe deformity of the foot and ankle [1-3]. There are a number of medical conditions with neuropathic manifestations that are linked to the development of Charcot foot [4], although diabetes has become the leading cause in the Western world [3-6]. The estimated prevalence of Charcot foot in the general diabetes population is $0.08 \%$, but can rise to $13 \%$ in high-risk foot populations [3, 4]. Acute Charcot neuroarthropathy typically presents as a warm, erythematous and oedematous foot $[7,8]$. As such, this condition is often masked by, or is clinically indistinguishable from deep vein thrombosis, inflammatory arthritis (e.g. gout) or infection (e.g. cellulitis, osteomyelitis). Consequently, this often leads to delayed or missed diagnosis in its early stages $[4,7,9]$.

Delayed diagnosis can result in devastating complications such as gross deformity, instability, recurrent ulceration and/or amputation [2, 3, 6, 9]. Structural damage to the foot and ankle can be limited, however, if acute Charcot foot is identified and managed early $[2,7,9]$. Total contact casting (TCC) is a treatment used to offload and immobilise the affected foot and ankle to prevent trauma, further fractures and destruction, and preserve the foot structure during the inflammatory phase $[10,11]$. The TCC slows the progression of the Charcot foot by controlling the cycle of inflammation and the degree of lower limb oedema $[3,5,8,11,12]$.

It is widely accepted that TCC is the preferred method of immobilisation for an acute Charcot foot, as it is customised and non-removable $[3,10,12]$. However, a common question from patients being treated with TCC is "this cast is hot and heavy; how long do I have to use it?" Duration of TCC treatment will depend upon the patient's response, but it is recommended that casting is continued until the temperature differential is less than $2{ }^{\circ} \mathrm{C}$ between the affected and non-affected Charcot foot for 4-6 consecutive weeks, and there are radiographic signs of healing $[3,8,13-16]$.

Globally, population-based studies have found significant discrepancies regarding the duration of TCC treatment for resolution of acute Charcot foot. In the United
Kingdom (UK), studies have reported treatment times of 9 to 12 months $[2,17,18]$, while data from the United States (US) [10, 11, 19, 20], Europe [21-28] and other Asia Pacific countries [29, 30] have reported shorter treatment times of 3 to 9 months. Unfortunately, none of the above-mentioned studies included Australian subjects. To date, there has only been one Australian study that has reported on TCC duration times for acute Charcot foot resolution. This study reported an average treatment time of approximately 10 months [31]. Therefore, there is limited data regarding the duration of TCC treatment for resolution of acute Charcot foot in the Australian population. To address this deficiency, this study conducted a retrospective analysis of cases presenting to a high-risk foot service (HRFS) with acute Charcot foot over a three-year period. This study specifically aimed to investigate the time to resolution of acute Charcot foot with TCC treatment, and to explore patient and clinical factors affecting its duration.

\section{Methods \\ Ethics approval}

The Human Research and Ethics Committee of Eastern Health (reference number: LR25/2015) approved the study. Informed consent was not required of participants due to the retrospective nature of the study, and data collection involved the use of existing medical records only.

\section{Study design}

This retrospective cohort study was conducted in a HRFS at a large metropolitan health network in Melbourne, Australia from 4 January 2012 to 4 January 2015. Clinical, demographic, medical imaging, and foot examination information were retrospectively collected from existing medical records and from medical imaging/pathology reports (Additional file 1).

\section{Participants}

All adults attending the HRFS over the three-year period with an acute Charcot foot (defined as modified Eichenholtz stage 0 or $1[16,32,33]$ ) were eligible for inclusion. Participants were excluded if they had a chronic Charcot foot (defined as modified Eichenholtz 
stage 2 or 3 [16, 32, 33]), concurrent rheumatic arthropathy, rheumatoid arthritis, psoriatic arthritis, gout, systemic lupus erythematosus, erysipelas, cellulitis, and/or osteomyelitis, had a TCC for management of a foot ulcer or fracture (i.e. not related to Charcot), or if they transferred/withdrew from the HRFS prior to resolution of their acute Charcot foot.

\section{Data collection}

Initially, all records from the HRFS were screened for eligibility based on the inclusion and exclusion criteria. One investigator (D.G.) reviewed hospital medical records for information relating to participant characteristics, comorbidities, foot assessment data, Charcot foot history, and TCC treatment. Data were checked for accuracy by another investigator (M.R.K.). The screening tool and data collection form used in this study can be found in Additional file 1.

Peripheral neuropathy was defined as a SemmesWeinstein $5.07 / 10 \mathrm{~g}$ monofilament score $<3 / 3$ over the plantar aspects of the hallux, 3rd and 5th metatarsals on either foot [34]. Peripheral arterial disease was defined as absence of $\geq 2$ pedal pulses [35], toe-brachial pressure index $\leq 0.6$, and/or ankle-brachial pressure index $\leq 0.9$ either foot $[35,36]$.

Acute Charcot foot (defined as modified Eichenholtz stage 0 or $1[16,32,33])$ was documented when at least one or more of the following clinical features were evident in the medical records AND there were conclusive diagnostic imaging findings:

- Clinical signs/symptoms (i.e. erythema, oedema, increased temperature, bounding pulses) \pm history of trauma or surgery \pm history of pain \pm structural deformity [3] or;

- More than $2{ }^{\circ} \mathrm{C}$ dermal temperature differential between the suspected Charcot foot and the contralateral foot $[2,3,5,13-15,22,37]$ or;

- Peripheral neuropathy (i.e. score of $<3 / 3$ on either foot with a $10 \mathrm{~g}$ monofilament test) $[1,3,5,34,38]$ and;

- Conclusive diagnostic imaging findings (e.g. osteopenia, fragmentation, joint subluxation, fractures) [16].

Charcot foot pattern was recorded according to its anatomical site(s) of involvement using the Sanders and Frykberg classification [6, 39]. Charcot foot history including duration of signs and symptoms consistent with acute Charcot foot prior to attending the HRFS, Charcot misdiagnosis, and potential Charcot triggers were recorded. This information was obtained via patient report within the HRFS progress notes.
The HRFS in this study used the following technique [40] for application of the serial TCCs (Fig. 1):

- 10-20 mm felt padding (i.e. D-filler) placed under the medial longitudinal arch (no felt padding applied in cases of severe 'rockerbottom' Charcot deformity);

- Cotton tube bandage applied to cover and protect the lower limb;

- $5 \mathrm{~mm}$ silicone strips cut to size and applied over bony prominences (e.g. anterior tibia, medial/lateral malleoli);

- Inner layer of plaster of paris applied, followed by an outer splint of fibreglass;

- Decision regarding toes in or out is made on an individual basis (e.g. personal preference, feelings of claustrophobia);

- Post-operative shoe (e.g. Darco ${ }^{\circ}$ used over TCC for protection during ambulation and;

- Patients may ambulate immediately post TCC application but are encouraged to avoid weightbearing on the affected side.

Duration of TCC treatment was defined as the number of days between the date of the first TCC application to the date of TCC cessation for the same episode of acute Charcot foot. In cases of unexpected removal of TCC (e.g. patient request, work/travel requirements), the time spent out of the TCC was included in the participant's overall TCC treatment time.

The decision to cease TCC treatment in the HRFS is guided by clinical assessment performed by experienced clinicians in Orthopaedics and Podiatry. Changes noted during clinical assessment include visual signs of reduced oedema, erythema and skin temperatures. Objective and quantifiable temperature testing is conducted using a hand-held infrared dermal thermometer (Exergen Corporation 'DermaTemp-1001'). After a 15-min acclimatisation period (i.e. following removal of the TCC and contralateral footwear/hosiery) [41], ten anatomical sites (plantar 1st/3rd/5th metatarsal heads, plantar aspect of base of 5th metatarsal [styloid process], dorsal aspect of base of 3rd metatarsal, medial aspect of base of 1st metatarsal, medial aspect of navicular, plantar medial tubercle of calcaneus, medial malleolus and lateral malleolus) are tested weekly, then extended out to fortnightly when oedema has stabilised [42].

In the HRFS, resolution of acute Charcot foot is determined based on the following:

- Modified Eichenholtz stage 3 or 4 Charcot foot [16, 32, 33] confirmed by medical imaging and/or;

- Dermal temperature differential less than $2^{\circ} \mathrm{C}$ for 6 consecutive weeks for all anatomical testing sites [3]. 


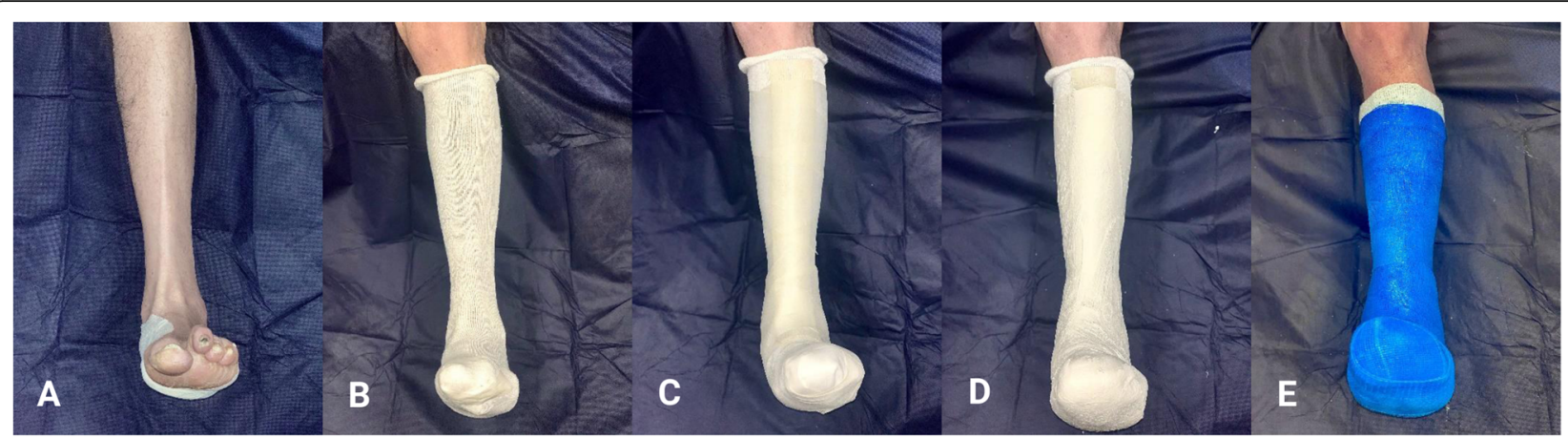

Fig. 1 Application of total contact cast. (A) Felt padding ('D-filler') is placed under medial longitudinal arch (except in cases of severe 'rockerbottom' deformity). (B) Cotton tube bandage is applied to protect lower limb and foot. (C) Silicone strips are applied over bony prominences. (D) Plaster of paris inner layer is applied. (E) Fibreglass outer layer is applied. Participant photographs printed with permission

Resolution of acute Charcot foot is then followed by transition into a Charcot Restraint Orthotic Walker (CROW), knee-high removable offloading boot (e.g. Controlled Ankle Motion [CAM] walker) or therapeutic footwear with custom foot orthoses [40].

\section{Data handling and statistical analysis}

Data were entered into a Microsoft Excel ${ }^{\circ}$ spreadsheet for the development of an analytical file. Participant data were initially checked for duplication (i.e. for those with multiple admissions to the HRFS). To ensure confidentiality and privacy of participants, all data were made nonidentifiable with the use of a coding system. Participant characteristics were calculated and expressed as mean (standard deviation, SD) or median (interquartile range, IQR, 25th to 75th percentile) for continuous variables and number (proportion) for categorical variables. Continuous data were checked for normality. To explore between-group differences (for example, TCC duration $<4$ or $>4$ months), independent samples $t$-tests, MannWhitney $U$ tests, Chi-square tests, and/or Fisher's exact tests were calculated depending on data type. To evaluate associations between recorded variables and duration of TCC treatment, mean differences, odds ratios (OR) and $95 \%$ confidence intervals $(\mathrm{CI})$ were calculated. IBM SPSS version 26.0 (IBM Corp, Somers, NY, USA) was used for statistical analysis.

\section{Results}

Of the 46 patient records screened, 27 adults with acute Charcot foot attending the HRFS between January 2012 and January 2015 were eligible for inclusion. Table 1 provides the participant characteristics. The mean age (SD) was 57.9 (12.6) years, $66.7 \%$ were male, and $29.6 \%$ had a smoking history (i.e. past or current smoker). The majority of participants had diabetes (88.9\%) with an average duration of 24.0 (SD, 13.3) years and glycated haemoglobin of $8.6 \%$ (SD, 2.0). Overall, there was a high prevalence of previous foot complications including foot ulceration (66.7\%), infection (63.0\%) and amputation (14.8\%). Peripheral neuropathy and peripheral arterial disease were present in 96.3 and 33.3\%, respectively (Table 2).

Charcot misdiagnosis occurred in $63.0 \%$ of participants, and signs and symptoms consistent with acute Charcot foot were present for a median of 2.0 (IQR, 1.0 to 6.0) months prior to presenting or being referred to the HRFS. The affected foot was most commonly misdiagnosed as cellulitis (47.1\%). All participants presented with a stage 1 Charcot foot. Of these, the majority were located in the tarsometatarsal joints $(44.4 \%)$ or midfoot $(40.7 \%)$ and were triggered by an ulcer or traumatic injury (85.2\%). All participants received x-ray imaging to establish diagnosis at initial presentation to the HRFS, while $14.8 \%$ also had a bone scan and/or magnetic resonance imaging (Table 3).

Throughout the study period, there were a total of 421 TCCs applied (average of 15 TCCs per participant). The median TCC duration for resolution of acute Charcot foot was 4.3 (IQR, 2.7 to 7.8) months. A large proportion of participants $(77.8 \%)$ were able to weightbear as tolerated using a post-operative shoe over the TCC. Overall, there were 21 complications/adverse events related to the TCC treatment, the majority being minor and reversible. Skin rubbing/irritation (40.7\%) and asymmetry pain $(22.2 \%)$ were the most common. The overall complication rate was $5 \%$ per cast (calculated from the total number of complications divided by the total number of TCCs i.e. 21/421). Post TCC treatment, almost half of the participants $(48.1 \%)$ transitioned into specialised or off-the-shelf footwear with custom foot orthoses, $25.9 \%$ used a life-long CROW, and $22.2 \%$ underwent soft tissue or bone reconstructive surgery. The median follow-up time from ceasing TCC treatment (due to Charcot resolution) to the end of the study period was 11.9 (IQR, 2.8 to 14.6) months. During this time, there were no 
Table 1 Participant characteristics

\begin{tabular}{|c|c|c|c|c|c|}
\hline \multirow[b]{2}{*}{ Variable } & \multirow[b]{2}{*}{$\begin{array}{l}\text { Total } \\
(\mathrm{N}=27)\end{array}$} & \multicolumn{2}{|c|}{ Median TCC duration } & \multirow[b]{2}{*}{$\begin{array}{l}\text { MD }(95 \% \mathrm{Cl})^{\dagger} \\
\text { or } \\
\text { OR }(95 \% \mathrm{Cl})\end{array}$} & \multirow[b]{2}{*}{$P$-value* } \\
\hline & & $\begin{array}{l}<4 \text { months } \\
(n=12)\end{array}$ & $\begin{array}{l}>4 \text { months } \\
(n=15)\end{array}$ & & \\
\hline Mean age (SD), years & $57.9(12.6)$ & $56.3(13.7)$ & $59.1(12.0)$ & $2.81(-7.40 \text { to } 13.02)^{\dagger}$ & 0.576 \\
\hline Male sex, $n(\%)$ & $18(66.7)$ & $8(66.7)$ & $10(66.7)$ & $1.00(0.20$ to 5.00$)$ & $>0.99$ \\
\hline Known ethanol abuse, $n$ (\%) & $6(22.2)$ & $4(33.3)$ & $2(13.3)$ & 0.31 (0.05 to 2.08) & 0.357 \\
\hline Smoking history, $n(\%)^{a}$ & $8(29.6)$ & $2(16.7)$ & $6(40.0)$ & 3.33 (0.53 to 20.91) & 0.236 \\
\hline Diabetes, n (\%) & $24(88.9)$ & $10(83.3)$ & $14(93.3)$ & $2.80(0.22$ to 35.29$)$ & 0.569 \\
\hline Type 1, n (\%) & $8(33.3)$ & $4(40.0)$ & $4(28.6)$ & 0.60 (0.11 to 3.34$)$ & 0.673 \\
\hline Type 2, n (\%) & $16(66.7)$ & $6(60.0)$ & $10(71.4)$ & 1.67 (0.30 to 9.27$)$ & 0.673 \\
\hline Mean duration (SD), years & $24.0(13.3)$ & $22.4(13.5)$ & $25.1(13.6)$ & $2.74(-8.87 \text { to } 14.36)^{\dagger}$ & 0.629 \\
\hline Mean HbA1c (SD), \% ${ }^{b}$ & $8.6(2.0)$ & $8.1(2.5)$ & $8.9(1.7)$ & $0.82(-0.99 \text { to } 2.63)^{\dagger}$ & 0.358 \\
\hline Dyslipidaemia, n (\%) & $16(59.3)$ & $6(50.0)$ & $10(66.7)$ & 2.00 (0.42 to 9.52$)$ & 0.452 \\
\hline Hypertension, n (\%) & $13(48.1)$ & $4(33.3)$ & $9(60.0)$ & $3.00(0.62$ to 14.62$)$ & 0.168 \\
\hline Ischaemic heart disease, $n$ (\%) & $3(11.1)$ & $1(8.3)$ & $2(13.3)$ & 1.69 (0.14 to 21.27) & $>0.99$ \\
\hline Congestive cardiac failure, $n$ (\%) & $0(0)$ & $0(0)$ & $0(0)$ & N/A & N/A \\
\hline Cerebrovascular disease, $n$ (\%) & $2(7.4)$ & $0(0)$ & $2(13.3)$ & $1.92(1.32$ to 2.80$)$ & 0.487 \\
\hline Chronic kidney disease, $n$ (\%) & $4(14.8)$ & $1(8.3)$ & $3(20.0)$ & 2.75 (0.25 to 30.51$)$ & 0.605 \\
\hline Osteoarthritis, n (\%) & $13(48.1)$ & $3(25.0)$ & $10(66.7)$ & $6.00(1.11$ to 32.55$)$ & $0.031^{*}$ \\
\hline Previous foot ulceration, $n$ (\%) & $18(66.7)$ & $7(58.3)$ & $11(73.3)$ & 1.96 (0.39 to 9.93$)$ & 0.448 \\
\hline Previous foot infection, $n$ (\%) & $17(63.0)$ & $7(58.3)$ & $10(66.7)$ & $1.43(0.30$ to 6.88$)$ & 0.706 \\
\hline Previous amputation, $n$ (\%) & $4(14.8)$ & $3(25.0)$ & $1(6.7)$ & 0.21 (0.02 to 2.39$)$ & 0.294 \\
\hline
\end{tabular}

Data are $\mathrm{n}(\%), \mathrm{MD}(95 \% \mathrm{Cl})$ or $\mathrm{OR}(95 \% \mathrm{Cl})$, unless otherwise specified. Percentages may not add up to $100 \%$, as they are rounded to the nearest percent $C l$, confidence interval; $H b A 1 C$, glycated haemoglobin; $M D$, mean difference; $N / A$, not applicable; $O R$, odds ratio; $S D$, standard deviation; $T C C$, total contact casting SI conversion factor: To convert $\mathrm{HbA1c}$ to proportion of total haemoglobin, multiply by 0.01

"Significant difference between ' $<4$ months' and '> 4 months' median TCC duration groups, $p<0.05$

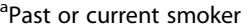

${ }^{\mathrm{b}}$ Maximum missing data were for glycated haemoglobin ( $\left.\mathrm{HbA} 1 \mathrm{c}\right)$ involving 1 participant overall (3.7\%)

${ }^{\dagger}$ Data are MD $(95 \% \mathrm{Cl})$, unless otherwise specified

recurrent Charcot feet recorded, however, contralateral Charcot foot occurred in 3 (11.1\%) participants (Table 4).

On comparison of participants with more or less than 4 months duration of TCC treatment, only osteoarthritis was significantly associated with a longer TCC duration (OR, 6.00; 95\% CI, 1.11 to 32.55; $p=0.031$ ). All other patient and clinical factors were non-significant (Tables 1 to 4 ).

From acute Charcot diagnosis to resolution, the greatest reduction in dermal temperature differential was seen at the medial aspect of the navicular $\left(-1.7^{\circ} \mathrm{C}\right)$, followed closely by the dorsal aspect of the base of the 3rd metatarsal, the medial aspect of the base of the 1st metatarsal, and the medial malleolus $\left(-1.5^{\circ} \mathrm{C}\right)$ (Table 5).

\section{Discussion}

This is one of the first studies to investigate duration of TCC treatment for resolution of acute Charcot foot in Australian subjects. Overall, this study found that the median duration of TCC treatment was 4.3 (IQR, 2.7 to 7.8) months. This finding is observed to be shorter than reports from studies in the UK (median, 9 to 12 months) $[2,17,18]$, but is mostly comparable to studies conducted in the US (mean, 3 to 5 months) [10, 11, 19, 20], Europe (mean, 3 to 9 months) [21-27], and other Asia Pacific countries, including Thailand (median, 5 months) [30] and New Zealand (mean, 5 months) [29]. Interestingly, this finding was lower than an earlier Australian study conducted in Perth, where the average TCC duration was approximately 10 months [31]. This global (and local) variation may be explained by differing participant characteristics, Charcot characteristics (e.g. pattern and stage), techniques and protocols for monitoring Charcot progression, definition of Charcot resolution, the type of offloading used and their respective protocols (e.g. initial treatment with TCC and then transitioning to removable walker) $[10,25,26]$, reduced access to services, staff capacity and experience in applying the TCCs, and study design $[2,20,21,43-46]$.

That being said, the available data on TCC duration are largely derived from retrospective and observational studies with small sample sizes, therefore, there is 
Table 2 Neurovascular foot assessments

\begin{tabular}{|c|c|c|c|c|c|}
\hline \multirow[b]{2}{*}{ Foot assessment/variable } & \multirow[b]{2}{*}{$\begin{array}{l}\text { Total } \\
(N=27)\end{array}$} & \multicolumn{2}{|c|}{ Median TCC duration } & \multirow[b]{2}{*}{ OR $(95 \% \mathrm{Cl})$} & \multirow[b]{2}{*}{$P$-value* } \\
\hline & & $\begin{array}{l}<4 \text { months } \\
(n=12)\end{array}$ & $\begin{array}{l}>4 \text { months } \\
(n=15)\end{array}$ & & \\
\hline Peripheral neuropathy ${ }^{a}$ & $26(96.3)$ & $11(91.7)$ & $15(100.0)$ & $0.42(0.27$ to 0.66$)$ & 0.444 \\
\hline \multicolumn{6}{|l|}{ Left } \\
\hline $0 / 3, n(\%)$ & $24(88.9)$ & $11(84.6)$ & $13(92.9)$ & & \\
\hline $1 / 3, n(\%)$ & $1(3.7)$ & $0(0)$ & $1(7.1)$ & & \\
\hline $2 / 3, n(\%)$ & $1(3.7)$ & $1(7.7)$ & $0(0)$ & & \\
\hline $3 / 3, n(\%)$ & $1(3.7)$ & $1(7.7)$ & $0(0)$ & & \\
\hline \multicolumn{6}{|l|}{ Right } \\
\hline $0 / 3, n(\%)$ & $24(88.9)$ & $11(84.6)$ & $13(92.9)$ & & \\
\hline $1 / 3, n(\%)$ & $1(3.7)$ & $1(7.7)$ & $0(0)$ & & \\
\hline $2 / 3, n(\%)$ & $0(0)$ & $0(0)$ & $0(0)$ & & \\
\hline $3 / 3, n(\%)$ & $2(7.4)$ & $1(7.7)$ & $1(7.1)$ & & \\
\hline Peripheral arterial disease $\mathrm{e}^{\mathrm{b}}$ & $9(33.3)$ & $4(33.3)$ & $5(33.3)$ & $1.00(0.20$ to 5.00$)$ & $>0.99$ \\
\hline \multicolumn{6}{|l|}{ Pedal pulses ${ }^{\dagger}$} \\
\hline $0 / 4, n(\%)$ & $1(3.7)$ & $1(7.7)$ & $0(0)$ & & \\
\hline $1 / 4, n(\%)$ & $1(3.7)$ & $0(0)$ & $1(7.1)$ & & \\
\hline $2 / 4, n(\%)$ & $4(14.8)$ & $2(15.4)$ & $2(14.3)$ & & \\
\hline $3 / 4, n(\%)$ & $1(3.7)$ & $0(0)$ & $1(7.1)$ & & \\
\hline $4 / 4, n(\%)$ & $19(70.4)$ & $10(76.9)$ & $9(64.3)$ & & \\
\hline \multicolumn{6}{|l|}{ Mean ABPI (SD) } \\
\hline Left $^{\dagger}$ & $1.15(0.20)$ & $1.11(0.21)$ & $1.20(0.20)$ & & \\
\hline Right $^{\dagger}$ & $1.11(0.23)$ & $1.08(0.15)$ & $1.16(0.33)$ & & \\
\hline \multicolumn{6}{|l|}{ Mean TBPI (SD) } \\
\hline Left $^{+}$ & $0.82(0.15)$ & $0.79^{c}$ & $0.83(0.21)$ & & \\
\hline Right $^{\dagger}$ & $0.66(0.17)$ & $0.78^{c}$ & $0.53^{c}$ & & \\
\hline \multicolumn{6}{|c|}{ Mean systolic toe pressure (SD) } \\
\hline Left $^{\dagger}$ & $105.4(11.6)$ & $118^{c}$ & $102.3(10.6)$ & & \\
\hline Right $^{\dagger}$ & 99.0 (13.9) & $109^{c}$ & 95.7 (15.0) & & \\
\hline
\end{tabular}

Data are $\mathrm{n}(\%)$ or mean (SD), unless otherwise specified. Percentages may not add up to $100 \%$, as they are rounded to the nearest percent

$A B P I$, ankle-brachial pressure index; $S D$, standard deviation; $T B P I$, toe-brachial pressure index; $T C C$, total contact casting

"Significant difference between '< 4 months' and '> 4 months' median TCC duration groups, $\mathrm{p}<0.05$

${ }^{a}$ Peripheral neuropathy was defined as a monofilament score $<3 / 3$ either foot

${ }^{b}$ Peripheral arterial disease was defined as absence of $\geq 2$ pedal pulses, TBPI $\leq 0.6$, and/or ABPI $\leq 0.9$ either foot

${ }^{+}$Maximum missing data were for right TBPI involving 25 participants overall $(92.6 \%)$. Missing data were for pedal pulses $(n=1)$, ABPI $(n=15)$, left TBPI $(n=24)$,

right systolic toe pressure $(n=23)$, and left systolic toe pressure $(n=20)$

${ }^{c}$ As a result of missing data pertaining to toe systolic pressures, ankle systolic pressures and/or TBPI scores, data reported are the raw data for one participant

only. Therefore, mean (SD) were unable to be calculated and reported

limited ability to determine temporal relationships with the reported clinical outcomes. The two largest studies in the literature includes a web-based observational study [2] with 288 acute Charcot cases from 76 centres in the UK and Ireland (although data on resolution were only available in 219 participants). The median duration of TCC treatment was 9 months [2]. Another study [28] that conducted a retrospective analysis on 164 participants with acute Charcot found the average TCC treatment time was 6 months [28]. Given that these two studies have the largest cohorts, and are likely to be the most clinically relevant, these figures may perhaps act as a benchmark for TCC duration more broadly.

There were five additional important findings from our study. First, those with osteoarthritis were 6-fold more likely to have a TCC duration of more than 4 months for acute Charcot foot resolution, compared to those without osteoarthritis (OR, 6.00; 95\% CI, 1.11 to $32.55 ; p=0.031$ ). While there is some evidence to suggest a relationship between rheumatoid arthritis and Charcot neuroarthropathy [47], to the authors' knowledge, no publications have reported Charcot 
Table 3 Charcot foot history

\begin{tabular}{|c|c|c|c|c|c|}
\hline \multirow[b]{2}{*}{ Variable } & \multirow[b]{2}{*}{$\begin{array}{l}\text { Total } \\
(\mathrm{N}=27)\end{array}$} & \multicolumn{2}{|c|}{ Median TCC duration } & \multirow[b]{2}{*}{ OR $(95 \% \mathrm{Cl})$} & \multirow[b]{2}{*}{$P$-value* } \\
\hline & & $\begin{array}{l}<4 \text { months } \\
(n=12)\end{array}$ & $\begin{array}{l}>4 \text { months } \\
(n=15)\end{array}$ & & \\
\hline \multicolumn{6}{|l|}{ Charcot foot } \\
\hline Left, $n(\%)$ & $14(51.9)$ & $4(33.3)$ & $10(66.7)$ & 4.00 (0.80 to 20.02$)$ & 0.085 \\
\hline Right, $n$ (\%) & $13(48.1)$ & $8(66.7)$ & $5(33.3)$ & $0.25(0.05$ to 1.25$)$ & 0.085 \\
\hline \multicolumn{6}{|l|}{ Stage of Charcot } \\
\hline Stage $0, n(\%)$ & $0(0)$ & $0(0)$ & $0(0)$ & N/A & N/A \\
\hline Stage $1, n(\%)$ & $27(100.0)$ & $12(100.0)$ & $15(100.0)$ & $\mathrm{N} / \mathrm{A}$ & N/A \\
\hline Median Charcot duration (IQR), months $s^{\mathrm{a}, \mathrm{b}}$ & $2.0(1.0$ to 6.0$)$ & $2.5(1.0$ to 6.0$)$ & 1.8 (0.9 to 6.8) & N/A & $0.709^{+}$ \\
\hline \multicolumn{6}{|l|}{ Charcot trigger } \\
\hline Ulceration, $n$ (\%) & $9(33.3)$ & $5(41.7)$ & $4(26.7)$ & 0.51 (0.10 to 2.57 ) & 0.448 \\
\hline Injury/trauma, n (\%) & $14(51.9)$ & $5(41.7)$ & $9(60.0)$ & 2.10 (0.45 to 9.84$)$ & 0.343 \\
\hline Amputation, $n(\%)$ & $2(7.4)$ & $2(16.7)$ & $0(0)$ & 1.20 (0.93 to 1.55$)$ & 0.188 \\
\hline Lymphoedema, n (\%) & $1(3.7)$ & $0(0)$ & $1(6.7)$ & 0.93 (0.82 to 1.07$)$ & $>0.99$ \\
\hline Unknown, $n$ (\%) & $1(3.7)$ & $0(0)$ & $1(6.7)$ & 0.93 (0.82 to 1.07$)$ & $>0.99$ \\
\hline Charcot misdiagnosis, $n$ (\%) & $17(63.0)$ & $7(58.3)$ & $10(66.7)$ & 1.43 (0.30 to 6.88) & 0.706 \\
\hline \multicolumn{6}{|l|}{ Charcot pattern } \\
\hline Tarsometatarsal joints, $n$ (\%) & $12(44.4)$ & $5(41.7)$ & $7(46.7)$ & $1.23(0.27$ to 5.67$)$ & 0.795 \\
\hline NC, TN, CC joints, $n$ (\%) & $11(40.7)$ & $6(50.0)$ & $5(33.3)$ & 0.50 (0.11 to 2.38) & 0.452 \\
\hline Ankle and subtalar joints, $n$ (\%) & $1(3.7)$ & $0(0)$ & $1(6.7)$ & 0.93 (0.82 to 1.07$)$ & $>0.99$ \\
\hline Combination, $n(\%)^{c}$ & $3(11.1)$ & $1(8.3)$ & $2(13.3)$ & 1.69 (0.14 to 21.3) & $>0.99$ \\
\hline \multicolumn{6}{|l|}{ Imaging received } \\
\hline $\mathrm{X}$-ray, $n$ (\%) & $27(100.0)$ & $12(100.0)$ & $15(100.0)$ & N/A & N/A \\
\hline Bone scan, $n(\%)$ & $4(14.8)$ & $0(0)$ & $4(26.7)$ & 0.73 (0.54 to 1.00$)$ & 0.106 \\
\hline MRI, $n(\%)$ & $4(14.8)$ & $2(16.7)$ & $2(13.3)$ & 0.77 (0.09 to 6.45$)$ & $>0.99$ \\
\hline
\end{tabular}

Data are $\mathrm{n}(\%)$ or OR $(95 \% \mathrm{Cl})$, unless otherwise specified. Percentages may not add up to $100 \%$, as they are rounded to the nearest percent

$C C$, calcaneocuboid; $C l$, confidence interval; $I Q R$, interquartile range; $M R I$, magnetic resonance imaging; $N / A$, not applicable; $N C$, naviculocuneiform; $O R$, odds ratio; $S D$, standard deviation; TCC, total contact casting; $T N$, talonavicular

"Significant difference between '< 4 months' and '> 4 months' median TCC duration groups, $\mathrm{p}<0.05$

${ }^{a}$ Approximate duration of signs and symptoms consistent with acute Charcot foot prior to attending the high-risk foot service. This information was obtained via patient report within the clinic

${ }^{\mathrm{b}}$ Maximum missing data were for Charcot duration involving 3 participants overall $(11.1 \%)$

${ }^{\mathrm{C}}$ Two participants (7.4\%) had a combination Charcot pattern involving the tarsometatarsal joints and the NC, TN and CC joints. One participant (3.7) had a combination Charcot pattern involving the calcaneus and the forefoot

${ }^{\dagger} P$-value relates to Mann-Whitney $U$ test

neuroarthropathy in association with osteoarthritis. Our finding that osteoarthritis may be associated with longer TCC duration (i.e. longer time to Charcot resolution) may be explained by the biomechanical (e.g. foot structure and function) and/or biochemical factors (e.g. chemokines, cytokines, growth factors) associated with osteoarthritis [48], which may be further exacerbated by the Charcot process. This finding, however, should be interpreted with caution due to the wide confidence interval. There were no other significant patient or clinical factors that affected TCC treatment time (i.e. when comparing those $<4$ or $>4$ months TCC duration), which is consistent with a previous study [15]. Due to the small sample size $(n=27)$ and retrospective nature of this study, high-quality prospective studies with large sample sizes are needed to confirm these findings.

Second, our findings relating to Charcot foot characteristics, including Charcot pattern and history of misdiagnosis, are similar to reports from previous studies $[21,31]$. In the current study, Charcot foot most commonly affected the tarsometatarsal joints $(44.4 \%)$ or midfoot $(40.7 \%)$. Overall, $85.2 \%$ were triggered by an ulcer or traumatic injury and were present for a median of 2.0 (IQR, 1.0 to 6.0) months prior to attending the HRFS. Charcot misdiagnosis occurred in $63.0 \%$ of participants prior to attending the HRFS, most commonly confused with cellulitis (47.1\%). Despite increased awareness, the acknowledged importance of Charcot-related patient education [49], and the publication of an evidence-based 
Table 4 Total contact casting treatment

\begin{tabular}{|c|c|c|c|c|c|}
\hline \multirow[b]{2}{*}{ Variable } & \multirow[b]{2}{*}{$\begin{array}{l}\text { Total } \\
(\mathrm{N}=27)\end{array}$} & \multicolumn{2}{|c|}{ Median TCC duration } & \multirow[b]{2}{*}{ OR $(95 \% \mathrm{Cl})$} & \multirow[b]{2}{*}{$P$-value* } \\
\hline & & $\begin{array}{l}<4 \text { months } \\
(n=12)\end{array}$ & $\begin{array}{l}>4 \text { months } \\
(n=15)\end{array}$ & & \\
\hline \multicolumn{6}{|l|}{ TCC applications } \\
\hline Total number & 421 & 101 & 320 & N/A & N/A \\
\hline Mean (SD), per participant & $15.6(9.2)$ & $8.4(2.3)$ & $21.3(8.5)$ & N/A & N/A \\
\hline \multicolumn{6}{|l|}{ TCC duration } \\
\hline Median (IQR), months & 4.3 (2.7 to 7.8$)$ & $2.6(2.1$ to 3.4$)$ & $6.0(4.4$ to 8.9$)$ & $\mathrm{N} / \mathrm{A}$ & N/A \\
\hline \multicolumn{6}{|l|}{ Ambulation status } \\
\hline Walking with post-operative shoe, $n(\%)$ & $21(77.8)$ & $10(83.3)$ & $11(73.3)$ & 0.55 (0.08 to 3.68$)$ & 0.662 \\
\hline Wheelchair bound, $n$ (\%) & $2(7.4)$ & $1(8.3)$ & $1(6.7)$ & 0.79 (0.04 to 14.03$)$ & $>0.99$ \\
\hline Crutches, $n$ (\%) & $3(11.1)$ & $1(8.3)$ & $2(13.3)$ & 1.69 (0.14 to 21.27) & $>0.99$ \\
\hline Scooter, $n$ (\%) & $1(3.7)$ & $0(0)$ & $1(6.7)$ & $0.93(0.82$ to 1.07$)$ & $>0.99$ \\
\hline Total number of complications/adverse events & 21 & 7 & 14 & $\mathrm{~N} / \mathrm{A}$ & N/A \\
\hline Complications/adverse events, $n$ (\%) & $16(59.3)$ & $6(50.0)$ & $10(66.7)$ & $2.00(0.42$ to 9.52$)$ & 0.452 \\
\hline Ulceration, $n$ (\%) & $2(7.4)$ & $0(0)$ & $2(13.3)$ & $0.87(0.71$ to 1.06$)$ & 0.487 \\
\hline Amputation, $n$ (\%) & $0(0)$ & $0(0)$ & $0(0)$ & $\mathrm{N} / \mathrm{A}$ & N/A \\
\hline Infection, n (\%) & $0(0)$ & $0(0)$ & $0(0)$ & N/A & N/A \\
\hline Deep vein thrombosis, $n$ (\%) & $0(0)$ & $0(0)$ & $0(0)$ & N/A & N/A \\
\hline Falls, $n(\%)$ & $0(0)$ & $0(0)$ & $0(0)$ & N/A & N/A \\
\hline Asymmetry pain, $n(\%)$ & $6(22.2)$ & $2(16.7)$ & $4(26.7)$ & $1.82(0.27$ to 12.17$)$ & 0.662 \\
\hline Rubbing/irritation, $n$ (\%) & $11(40.7)$ & $5(41.7)$ & $6(40.0)$ & $0.93(0.20$ to 4.37$)$ & $>0.99$ \\
\hline Self-inflicted, $n(\%)$ & $0(0)$ & $0(0)$ & $0(0)$ & N/A & N/A \\
\hline Other, $n(\%)^{a}$ & $2(7.4)$ & $0(0)$ & $2(13.3)$ & $0.87(0.71$ to 1.06$)$ & 0.487 \\
\hline None, $n(\%)$ & $11(40.7)$ & $6(50.0)$ & $5(33.3)$ & $1.00(0.20$ to 5.00$)$ & $>0.99$ \\
\hline \multicolumn{6}{|l|}{ Treatment after TCC } \\
\hline Specialised footwear and custom foot orthoses, $n$ (\%) & $13(48.1)$ & $4(33.3)$ & $9(60.0)$ & $3.00(0.62$ to 14.62$)$ & 0.168 \\
\hline Life-long CROW, $n$ (\%) & $7(25.9)$ & $5(41.7)$ & $2(13.3)$ & $0.22(0.03$ to 1.41$)$ & 0.185 \\
\hline Reconstructive/bone surgery, $n$ (\%) & $4(14.8)$ & $1(8.3)$ & $3(20.0)$ & 2.75 (0.25 to 30.51$)$ & 0.605 \\
\hline Soft tissue surgery, $n$ (\%) & $2(7.4)$ & $1(8.3)$ & $1(6.7)$ & 0.79 (0.04 to 14.03) & $>0.99$ \\
\hline CAM walker, $n$ (\%) & $1(3.7)$ & $1(8.3)$ & $0(0)$ & 1.09 (0.92 to 1.29$)$ & 0.444 \\
\hline Recurrent Charcot foot, $n$ (\%) & $0(0)$ & $0(0)$ & $0(0)$ & N/A & N/A \\
\hline Contralateral Charcot foot, $n$ (\%) & $3(11.1)$ & $1(8.3)$ & $2(13.3)$ & 1.69 (0.14 to 21.27) & $>0.99$ \\
\hline \multicolumn{6}{|l|}{ Charcot pattern } \\
\hline Tarsometatarsal joints, n (\%) & $1(33.3)$ & $0(0)$ & $1(50.0)$ & N/A & N/A \\
\hline NC, TN, CC joints, $n$ (\%) & $1(33.3)$ & $0(0)$ & $1(50.0)$ & N/A & N/A \\
\hline Ankle and subtalar joints, $n$ (\%) & $0(0)$ & $0(0)$ & $0(0)$ & N/A & N/A \\
\hline Combination, $n(\%)^{\mathrm{b}}$ & $1(33.3)$ & $1(100.0)$ & $0(0)$ & N/A & N/A \\
\hline
\end{tabular}

Data are $\mathrm{n}(\%)$ or OR $(95 \% \mathrm{Cl})$, unless otherwise specified. Percentages may not add up to $100 \%$, as they are rounded to the nearest percent $C A M$, controlled ankle motion; $C C$, calcaneocuboid; $C l$, confidence interval; $C R O W$, Charcot restraint orthotic walker; $I Q R$, interquartile range; $N / A$, not applicable; $N C$, naviculocuneiform; $O R$, odds ratio; $S D$, standard deviation; TCC, total contact casting; $T N$, talonavicular

"Significant difference between ' $<4$ months' and '> 4 months' median TCC duration groups, $\mathrm{p}<0.05$

${ }^{a}$ One participant (3.7\%) developed dermatitis. One participant (3.7\%) experienced a plaster saw cut on removal of TCC

${ }^{\mathrm{b}}$ One participant (3.7\%) had a combination Charcot pattern involving the tarsometatarsal joints and the NC, TN and CC joints

pathway [3], disparity still remains for early diagnosis [31]. Our findings support close monitoring for signs of Charcot foot in those with ulceration or reported traumatic injury to the foot. Furthermore, in those presenting with a warm, erythematous and/or oedematous foot, Charcot diagnosis should be considered, and the foot treated as such, until proven otherwise [8]. This is particularly important for high-risk 
Table 5 Dermal temperatures

\begin{tabular}{|c|c|c|c|c|}
\hline Site & Anatomical location & $\begin{array}{l}\text { Average temperature } \\
\text { differential at acute Charcot } \\
\text { diagnosis } \\
\left({ }^{\circ} \mathrm{C}\right)^{\mathrm{a}}\end{array}$ & $\begin{array}{l}\text { Average temperature } \\
\text { differential at acute Charcot } \\
\text { resolution } \\
\left({ }^{\circ} \mathrm{C}\right)^{\mathrm{a}}\end{array}$ & $\begin{array}{l}\text { Diagnosis minus resolution for } \\
\text { average temperature differential } \\
\left({ }^{\circ} \mathrm{C}\right)^{\mathrm{b}}\end{array}$ \\
\hline 1 & Plantar 1st metatarsal head & $2.5(2.2)$ & $1.3(1.6)$ & 1.2 \\
\hline 2 & Plantar 3rd metatarsal head & $2.8(2.0)$ & $1.4(2.2)$ & 1.4 \\
\hline 3 & Plantar 5th metatarsal head & $2.6(2.2)$ & $1.2(1.8)$ & 1.4 \\
\hline 4 & $\begin{array}{l}\text { Plantar aspect of the base of the } \\
5 \text { th metatarsal (styloid process) }\end{array}$ & $2.4(1.3)$ & $1.1(1.3)$ & 1.3 \\
\hline 5 & $\begin{array}{l}\text { Dorsal aspect of the base of the } \\
\text { 3rd metatarsal }\end{array}$ & $2.9(2.2)$ & $1.4(1.5)$ & 1.5 \\
\hline 6 & $\begin{array}{l}\text { Medial aspect of the base of the } \\
\text { 1st metatarsal }\end{array}$ & $3.0(2.1)$ & $1.5(1.8)$ & 1.5 \\
\hline 7 & Medial aspect of the navicular & $3.0(1.7)$ & $1.3(1.3)$ & 1.7 \\
\hline 8 & $\begin{array}{l}\text { Plantar medial tubercle of the } \\
\text { calcaneus }\end{array}$ & $1.6(1.4)$ & $0.7(1.1)$ & 0.9 \\
\hline 9 & Medial malleolus & $2.6(1.7)$ & $1.1(1.3)$ & 1.5 \\
\hline 10 & Lateral malleolus & $2.9(1.5)$ & $1.7(1.3)$ & 1.2 \\
\hline
\end{tabular}

Data are mean (SD), unless otherwise specified

$S D$, standard deviation

${ }^{a}$ Average temperature differential between the Charcot foot and the contralateral foot at specific anatomical sites

${ }^{b}$ Average temperature differential at diagnosis minus the average temperature differential at resolution (i.e. average temperature reduction from acute Charcot

diagnosis to resolution)

patients with long-standing diabetes and neuropathy $[3,21]$.

Third, of the 421 TCCs applied, there were 21 complications in total. This equates to an overall complication rate of $5 \%$ per cast, which is consistent with a previous study [50]. Overall, 59.3\% of participants experienced a complication or adverse event, the majority being minor and reversible. The most common complications were skin rubbing/irritation (61.1\%) and asymmetry pain (33.3\%). Previous studies have shown that the duration of non-removable (e.g. TCC) versus removable offloading devices (e.g. Aircast, CAM walker) for Charcot resolution is significantly less [2,31]. Given that the use of non-removable offloading can shorten the median time to resolution by approximately 3 months [2], this option may appeal to patients with Charcot foot due to the known physical, mental and social consequences of prolonged offloading (e.g. muscle atrophy, reduced activity levels and fitness, weight gain, poor glycaemic control, risk of falls, loss of work or income, offloading-related stigma, reduced health-related quality of life, inability to participate in certain family activities) $[1,5]$. Our findings and those of a previous study [50] support that TCC is a relatively safe modality for offloading and immobilising neuropathic feet, despite some expected minor and reversible complications [50]. However, it is still essential when considering TCC treatment that the risks and benefits are carefully considered, and that patients are fully informed of these risks prior to their first TCC application.
Fourth, a large proportion of participants experienced good clinical outcomes post TCC treatment. Almost half were able to return to specialised or off-the-shelf footwear and custom foot orthoses (48.1\%), while the other half with more severe cases of Charcot foot chose to wear a life-long CROW (25.9\%) or had soft tissue or bone reconstructive surgery $(22.2 \%)$. Fortunately, there were no recurrent Charcot feet recorded, which is consistent with other studies $[15,26]$. Contralateral Charcot foot occurred in 3 (11.1\%) participants. Therefore, to reduce the risk of bilateral Charcot, it is essential to ensure contralateral footwear is appropriate and an offloading foot orthotic is fitted [3]. As this study only collected data over a three-year period, longitudinal, prospective studies are needed to evaluate these clinical outcomes further.

Fifth, from acute Charcot diagnosis to resolution, the greatest reduction in temperature differential (i.e. when performing dermal temperature measurements at 10 commonly used anatomical sites) was seen at the medial aspect of the navicular $\left(-1.7^{\circ} \mathrm{C}\right)$, followed closely by the dorsal aspect of the base of the 3rd metatarsal, the medial aspect of the base of the 1st metatarsal, and the medial malleolus $\left(-1.5^{\circ} \mathrm{C}\right)$. This reduction in temperature differential is supported by a previous study [14]. Considering that the highest dermal temperatures often correlate with the joints affected by Charcot [3, 51, 52], this may explain why a greater temperature reduction was seen at these anatomical sites (i.e. as the majority of Charcot feet 
in this study affected the tarsometatarsal and midfoot joints). This finding provides valuable information regarding the expected reduction in temperature differential for each specific anatomical testing site at Charcot resolution, which may assist clinicians in monitoring Charcot progression.

This study has the limitations of a retrospective design and small sample size. To address the potential for selection bias, all participants that met the strict study eligibility criteria within the available sample were included. Therefore, the risk of selection bias was negligible or essentially non-existent. Due to the small sample size $(n=$ 27), there is an increased likelihood of the study being underpowered, which may have increased the risk for type II statistical errors. For example, the ability to detect differences between the TCC groups (i.e. $<4$ months and $>4$ months duration). However, as all eligible participants were exhausted from the available sample, the maximum sample size was reached. Therefore, it was not possible to increase the sample size of the current study. Another limitation relates to having no data or measurements pertaining to the degree of adherence to the TCC treatment. However, as this was a nonremovable device, poor adherence to treatment was unlikely. Regarding external validity, our findings are mostly generalisable to patients presenting with modified Eichenholtz stage 1 Charcot foot and those with diabetes (88.9\% of the cohort). In addition, as this study only included participants from a single metropolitan health service, this may affect the applicability of the findings to the broader Australian context. Finally, in cases of unexpected removal (e.g. patient request, work/travel requirements), the time spent out of the TCC was included in the participant's overall TCC treatment time. As a result, this may have slightly increased the study's calculated median TCC duration. However, to ensure this study remained pragmatic and clinically relevant, the authors' decision to include time spent out of the TCC was relevant.

Despite these limitations, this is one of the first studies to investigate duration of TCC treatment for resolution of acute Charcot foot in Australian subjects. This study had a rigorous inclusion and exclusion criteria, sound HRFS protocols using objective measurements (e.g. dermal temperatures and medical imaging findings) for monitoring the progression and resolution of acute Charcot, and expert TCC plaster technicians who used the same application technique for each cast (Fig. 1).

Large, high-quality, prospective studies are required to confirm the findings of this study and those reported in previous literature $[2,10,11,17-31]$. Future research may be directed towards investigating TCC duration for: (i) removable (e.g. CROW, CAM walker) versus nonremovable (e.g. TCC, iTCC) offloading devices for Charcot treatment, including an evaluation of treatment adherence (e.g. installing an accelerometer into a removable offloading device, as per a previous study [53]);

(ii) non diabetes-related Charcot neuroarthropathy;

(iii) patients with/without diabetes or with varying diabetes duration and/or;

(iv) different stages of Charcot foot.

There is also a need for longitudinal studies to evaluate adverse clinical outcomes, such as Charcot recurrence rates, development of contralateral Charcot, and rates of Charcot-related foot ulcers, infections and amputations.

Importantly, this study provides insight into the duration of TCC treatment for resolution of acute Charcot foot in Australian subjects, with comparisons made to the global body of evidence. Patient characteristics, Charcot foot presentations, TCC complications, factors affecting TCC duration, and post-TCC clinical outcomes have also been explored. The findings may provide recommendations and assist clinicians in relaying evidenced-based education for patients newly diagnosed with Charcot foot. Further, the findings may also assist Australian metropolitan settings (i.e. that follow a similar treatment protocol to the one described in this study) by developing HRFS patient pathways and expected resource requirements, clinical decision making for offloading treatment plans, managing patient expectations and goals, developing risk reduction plans, and improving overall adherence to TCC treatment for acute Charcot neuroarthropathy cases in HRFS throughout Australia. However, it is important to consider these findings and possible applications in the context of the study's limitations, the variation of TCC treatment times between the current study and an existing Australian study [31], and the broad TCC duration found in this study (IQR, 2.7 to 7.8 months).

\section{Conclusions}

This is one of the first studies to investigate the duration of TCC treatment for resolution of acute Charcot foot in Australian subjects. The median time to resolution was 4 months, which is shorter or comparable to data reported in the UK, US, Europe, and other Asia Pacific countries. Osteoarthritis was significantly associated with a longer TCC duration. The findings from this study may assist clinicians in providing patient education, managing expectations and improving adherence to TCC treatment for acute Charcot neuroarthropathy cases in Australia. Highquality, prospective, longitudinal, multi-centre studies are now needed to confirm the findings of this study and to provide a broader application to the Australian context. 


\section{Abbreviations}

CAM: Controlled ankle motion; Cl: Confidence interval; CROW: Charcot restraint orthotic walker; HRFS: High-risk foot service; IQR: Interquartile range; iTCC: Instant total contact cast; OR: Odds ratio; SD: Standard deviation; TCC: Total contact casting; UK: United Kingdom; US: United States

\section{Supplementary Information}

The online version contains supplementary material available at https://doi. org/10.1186/s13047-021-00477-5.

Additional file 1. Adobe professional. Screening tool and data collection form. Screening tool used to identify eligible participants and data collection form used to collate the participant data.

\section{Acknowledgements}

The authors would like to acknowledge the Maroondah Hospital HRFS at Eastern Health for their support of the project. The authors would like to acknowledge Matthew Donato from Eastern Health for his assistance with the development of the data collection form.

\section{Authors' contributions}

All authors contributed to the study conception and design. M.R.K. completed the ethics application. D.G. acquired the data. M.R.K. checked the data for accuracy. All authors assembled and quality controlled the data. All authors performed the analysis of the data and contributed to the interpretation of the data. All authors had full access to the data in the study and take responsibility for the integrity of the data and the accuracy of the data analysis. All authors drafted the first version of the manuscript. All authors read and approved the final manuscript prior to submission.

\section{Authors' information}

D.G. completed a Bachelor of Podiatry at La Trobe University in 1994. Since then, D.G. has also completed a Certificate 4 in training and assessment at Swinburne University and a Certificate 4 in Frontline Management at Box Hill Tafe. D.G. currently works as a Senior Podiatrist at Eastern Health. D.G. holds memberships with the Australian Health Practitioner Regulation Agency, the Advanced Practicing Podiatrists High Risk Foot Group and Wounds Australia. M.R.K. completed a Bachelor of Podiatry (Honours) at La Trobe University in 2009 and later completed her PhD at La Trobe University in 2017 for a study titled 'Risk factors for foot ulceration in adults with end-stage renal disease on dialysis'. M.R.K. currently works as a Senior Podiatrist at St Vincent's Hospital Melbourne and is a Lecturer in Podiatry at La Trobe University. M.R.K. holds memberships with the Australian Health Practitioner Regulation Agency, the Australian Podiatry Association and Wounds Australia.

\section{Funding}

The authors declare that no funding or sponsorship was received for this study.

\section{Availability of data and materials}

All data generated or analysed during this study are included in this published article and its supplementary information files.

\section{Declarations}

\section{Ethics approval and consent to participate}

The Human Research and Ethics Committee of Eastern Health (reference number: LR25/2015) approved the study. Informed consent was not required of participants due to the retrospective nature of the study, and data collection involved the use of existing medical records only.

\section{Consent for publication}

The results presented in this paper have not been published previously in whole or part, except in abstract form. Participant photographs were reprinted with permission.

\section{Competing interests}

The authors declare that they have no competing interests.

\section{Author details}

${ }^{1}$ Department of Podiatry, Eastern Health, Melbourne, Victoria 3135, Australia. ${ }^{2}$ Discipline of Podiatry, School of Allied Health, Human Services and Sport, La Trobe University, Melbourne, Victoria 3086, Australia. ${ }^{3}$ Department of Podiatry, St Vincent's Hospital Melbourne, Melbourne, Victoria 3065, Australia.

Received: 4 October 2020 Accepted: 29 April 2021

Published online: 15 June 2021

\section{References}

1. Christensen TM, Gade-Rasmussen B, Pedersen LW, Hommel E, Holstein PE, Svendsen OL. Duration of off-loading and recurrence rate in Charcot osteoarthropathy treated with less restrictive regimen with removable walker. J Diabetes Complicat. 2012;26(5):430-4. https://doi.org/10.1016/j.jdiacomp.2 012.05.006.

2. Game FL, Catlow R, Jones GR, Edmonds ME, Jude EB, Rayman G, et al. Audit of acute Charcot's disease in the UK: the CDUK study. Diabetologia. 2012; 55(1):32-5. https://doi.org/10.1007/s00125-011-2354-7.

3. Milne TE, Rogers JR, Kinnear EM, Martin HV, Lazzarini PA, Quinton TR, et al. Developing an evidence-based clinical pathway for the assessment, diagnosis and management of acute Charcot Neuro-Arthropathy: a systematic review. J Foot Ankle Res. 2013;6(1):30. https://doi.org/10.1186/1 757-1146-6-30.

4. Frykberg RG, Belczyk R. Epidemiology of the Charcot foot. Clin Podiatr Med Surg. 2008;25(1):17-28. https://doi.org/10.1016/j.cpm.2007.10.001.

5. Rogers LC, Frykberg RG, Armstrong DG, Boulton AJ, Edmonds M, Van GH, et al. The Charcot foot in diabetes. Diabetes Care. 2011;34(9):2123-9. https://doi.org/10.2337/dc11-0844.

6. Varma AK. Charcot neuroarthropathy of the foot and ankle: a review. J Foot Ankle Surg. 2013;52(6):740-9. https://doi.org/10.1053/j.jas.2013.07.001.

7. Markakis K, Bowling FL, Boulton AJ. The diabetic foot in 2015: an overview. Diabetes Metab Res Rev. 2016;32(Suppl 1):169-78. https://doi.org/10.1002/ dmrr.2740.

8. Boulton AJM, Whitehouse RW. The diabetic foot. [updated 15 mar 2020]. In: Feingold KR, Anawalt B, Boyce a, et al., editors. Endotext [internet]. South Dartmouth: MDText.com, Inc.; 2000. https://www.ncbi.nlm.nih.gov/books/ NBK409609/. Accessed 14 Jul 2020

9. Wukich DK, Sung W, Wipf SA, Armstrong DG. The consequences of complacency: managing the effects of unrecognized Charcot feet. Diabet Med. 2011;28(2):195-8. https://doi.org/10.1111/j.1464-5491.2010. 03141.x.

10. Pinzur MS, Lio T, Posner M. Treatment of Eichenholtz stage I Charcot foot arthropathy with a weightbearing total contact cast. Foot Ankle Int. 2006; 27(5):324-9. https://doi.org/10.1177/107110070602700503.

11. de Souza LJ. Charcot arthropathy and immobilization in a weight-bearing total contact cast. J Bone Joint Surg Am. 2008;90(4):754-9. https://doi.org/1 0.2106/JBJS.F.01523

12. Vopat ML, Nentwig MJ, Chong ACM, Agan JL, Shields NN, Yang SY. Initial diagnosis and management for acute Charcot neuroarthropathy. Kans J Med. 2018;11(4):114-9. https://doi.org/10.17161/kjm.v11i4.8709.

13. van Netten JJ, Prijs M, van Baal JG, Liu C, van der Heijden F, Bus SA. Diagnostic values for skin temperature assessment to detect diabetesrelated foot complications. Diabetes Technol Ther. 2014;16(11):714-21. https://doi.org/10.1089/dia.2014.0052.

14. McGill M, Molyneaux L, Bolton T, loannou K, Uren R, Yue DK. Response of Charcot's arthropathy to contact casting: assessment by quantitative techniques. Diabetologia. 2000;43(4):481-4. https://doi.org/10.1007/s0012 50051332.

15. Moura-Neto A, Fernandes TD, Zantut-Wittmann DE, Trevisan RO, Sakaki MH, Santos AL, et al. Charcot foot: skin temperature as a good clinical parameter for predicting disease outcome. Diabetes Res Clin Pract. 2012;96(2):e11-4. https://doi.org/10.1016/j.diabres.2011.12.029.

16. Rosenbaum AJ, DiPreta JA. Classifications in brief: Eichenholtz classification of Charcot arthropathy. Clin Orthop Relat Res. 2015;473(3):1168-71. https://doi.org/10.1007/s11999-014-4059-y.

17. Bates M, Petrova NL, Edmonds ME. How long does it take to progress from cast to shoes in the management of Charcot osteoarthropathy? Diabet Med. 2006;23(Suppl 2):1-30.

18. Stark C, Murray T, Gooday C, Nunney I, Hutchinson R, Loveday D, et al. 5 year retrospective follow-up of new cases of Charcot neuroarthropathy - a 
single Centre experience. Foot Ankle Surg. 2016;22(3):176-80. https://doi. org/10.1016/j.fas.2015.07.003

19. Armstrong DG, Todd WF, Lavery LA, Harkless LB, Bushman TR. The natural history of acute Charcot's arthropathy in a diabetic foot specialty clinic. Diabet Med. 1997;14(5):357-63. https://doi.org/10.1002/(SICI)1096-9136(1 99705)14:5<357::AID-DIA341>3.0.CO;2-8.

20. Sinacore DR. Acute Charcot arthropathy in patients with diabetes mellitus: healing times by foot location. J Diabetes Complicat. 1998;12(5):287-93. https://doi.org/10.1016/S1056-8727(98)00006-3.

21. Chantelau E. The perils of procrastination: effects of early vs. delayed detection and treatment of incipient Charcot fracture. Diabet Med. 2005; 22(12):1707-12. https://doi.org/10.1111/j.1464-5491.2005.01677.x.

22. Pakarinen TK, Laine HJ, Honkonen SE, Peltonen J, Oksala H, Lahtela J. Charcot arthropathy of the diabetic foot. Current concepts and review of 36 cases. Scand J Surg. 2002;91 (2):195-201. https://doi.org/10.1177/1457496902 09100212

23. Chantelau EA, Antoniou S, Zweck B, Haage P. Follow up of MRI bone marrow edema in the treated diabetic Charcot foot - a review of patient charts. Diabet Foot Ankle. 2018;9(1):1466611. https://doi.org/10.1080/200062 5X.2018.1466611.

24. Kimmerle R, Chantelau E. Weight-bearing intensity produces Charcot deformity in injured neuropathic feet in diabetes. Exp Clin Endocrinol Diabetes. 2007;115(06):360-4. https://doi.org/10.1055/s-2007-970578.

25. Renner N, Wirth SH, Osterhoff G, Böni T, Berli M. Outcome after protected full weightbearing treatment in an orthopedic device in diabetic neuropathic arthropathy (Charcot arthropathy): a comparison of unilaterally and bilaterally affected patients. BMC Musculoskelet Disord. 2016;17(1):504. https://doi.org/10.1186/s12891-016-1357-4

26. Ruotolo V, Di Pietro B, Giurato L, Masala S, Meloni M, Schillaci O, et al. A new natural history of Charcot foot: clinical evolution and final outcome of stage 0 Charcot neuroarthropathy in a tertiary referral diabetic foot clinic. Clin Nucl Med. 2013;38(7):506-9. https://doi.org/10.1097/RLU.0b013e318292eecb.

27. Zampa V, Bargellini I, Rizzo L, Turini F, Ortori S, Piaggesi A, et al. Role of dynamic MRI in the follow-up of acute Charcot foot in patients with diabetes mellitus. Skelet Radiol. 2011;40(8):991-9. https://doi.org/10.1007/ s00256-010-1092-0.

28. Sämann A, Pofahl S, Lehmann T, Voigt B, Victor S, Möller F, et al. Diabetic nephropathy but not $\mathrm{HbA1} \mathrm{c}$ is predictive for frequent complications of Charcot feet - long-term follow-up of 164 consecutive patients with 195 acute Charcot feet. Exp Clin Endocrinol Diabetes. 2012;120(6):335-9. https://doi.org/10.1055/s-0031-1299705.

29. Dixon J, Coulter J, Garrett M, Cutfield R. A retrospective audit of the characteristics and treatment outcomes in patients with diabetesrelated Charcot neuropathic osteoarthropathy. N Z Med J. 2017; 130(1467):62-7.

30. Thewjitcharoen Y, Parksook W, Krittiyawong S, Porramatikul S, Sripatpong J, Mahaudomporn S, et al. A closer look at outcome of diabetic Charcot foot: Thailand's perspective. Diabetes Res Clin Pract. 2014;1:S63.

31. Jilbert EJ, Schoen DE, Trewben BC, Gurr JM. A retrospective audit of active Charcot neuroarthropathy in a tertiary hospital podiatry department. J Foot Ankle Res. 2011;4 Suppl 1:P30.

32. Eichenholtz SN. Charcot joints. Springfield, IL, USA: Charles C. Thomas; 1966.

33. Shibata T, Tada K, Hashizume C. The results of arthrodesis of the ankle for leprotic neuroarthropathy. J Bone Joint Surg Am. 1990;72(5):749-56. https://doi.org/10.2106/00004623-199072050-00016.

34. Feng Y, Schlösser FJ, Sumpio BE. The Semmes Weinstein monofilament examination as a screening tool for diabetic peripheral neuropathy. J Vasc Surg. 2009;50(3):675-82. https://doi.org/10.1016/j.jvs.2009.05.017.

35. Armstrong DW, Tobin C, Matangi MF. The accuracy of the physical examination for the detection of lower extremity peripheral arterial disease. Can J Cardiol. 2010;26(10):e346-50. https://doi.org/10.1016/S0828-282X(1 0)70467-0.

36. Kaminski MR, Raspovic A, McMahon LP, Erbas B, Landorf KB. Risk factors for foot ulceration in adults with end-stage renal disease on dialysis: study protocol for a prospective observational cohort study. J Foot Ankle Res. 2015;8(1):53. https://doi.org/10.1186/s13047-015-0110-9.

37. Petrova NL, Moniz C, Elias DA, Buxton-Thomas M, Bates M, Edmonds ME. Is there a systemic inflammatory response in the acute Charcot foot? Diabetes Care. 2007;30(4):997-8. https://doi.org/10.2337/dc06-2168.

38. Sinacore DR, Hastings MK, Bohnert KL, Fielder FA, Villareal DT, Blair VP 3rd, et al. Inflammatory osteolysis in diabetic neuropathic (Charcot) arthropathies of the foot. Phys Ther. 2008;88(11):1399-407. https://doi.org/10.2522/ptj.2 0080025.

39. Sanders $L$, Frykberg RG. The Charcot foot. In: Frykberg RG, editor. The high risk foot in diabetes mellitus. New York: Churchill Livingstone; 1991. p. 325-35.

40. Kominsky SJ. The ambulatory total contact cast. In: Frykberg RG, editor. The high risk foot in diabetes mellitus. New York: Churchill Livingstone; 1991. p. 449-55.

41. Sun P-C, Jao S-HE, Cheng C-K. Assessing foot temperature using infrared thermography. Foot Ankle Int. 2005;26(10):847-53. https://doi.org/10.1177/1 07110070502601010.

42. Dallimore SM, Puli N, Kim D, Kaminski MR. Infrared dermal thermometry is highly reliable in the assessment of patients with Charcot neuroarthropathy. J Foot Ankle Res. 2020;13(1):56. https://doi.org/10.1186/s13047-020-00421-z.

43. Gooday C, Gray K, Game F, Woodburn J, Poland F, Hardeman W. Systematic review of techniques to monitor remission of acute Charcot neuroarthropathy in people with diabetes. Diabetes Metab Res Rev. 2020;36:e3328.

44. Chantelau E, Kimmerle R, Poll LW. Nonoperative treatment of neuroosteoarthropathy of the foot: do we need new criteria? Clin Podiatr Med Surg. 2007;24(3):483-503. https://doi.org/10.1016/j.cpm.2007.03.006.

45. Verity S, Sochocki M, Embil JM, Trepman E. Treatment of Charcot foot and ankle with a prefabricated removable walker brace and custom insole. Foot Ankle Surg. 2008;14(1):26-31. https://doi.org/10.1016/j.fas.2007.10.002.

46. Wukich DK, Sung W. Charcot arthropathy of the foot and ankle: modern concepts and management review. J Diabetes Complicat. 2009;23(6):409-26. https://doi.org/10.1016/j.jdiacomp.2008.09.004.

47. Grear BJ, Rabinovich A, Brodsky JW. Charcot arthropathy of the foot and ankle associated with rheumatoid arthritis. Foot Ankle Int. 2013;34(11):1541-7. https://doi.org/10.1177/1071100713500490.

48. lagnocco A, Rizzo C, Gattamelata A, Vavala C, Ceccarelli F, Cravotto E, et al. Osteoarthritis of the foot: a review of the current state of knowledge. Med Ultrason. 2013;15(1):35-40. https://doi.org/10.11152/mu.2013.2066.151.ail ofr2.

49. Bullen B, Young M, McArdle C, Ellis M. Charcot neuroarthropathy patient education among podiatrists in Scotland: a modified Delphi approach. J Foot Ankle Res. 2018;11(1):54. https://doi.org/10.1186/s13047-018-0296-8.

50. Guyton GP. An analysis of iatrogenic complications from the total contact cast. Foot Ankle Int. 2005;26(11):903-7. https://doi.org/10.1177/10711 0070502601101

51. Armstrong DG, Lavery LA. Monitoring healing of acute Charcot's arthropathy with infrared dermal thermometry. J Rehabil Res Dev. 1997; 34(3):317-21.

52. Bramham R, Wraight P, May K. Management of Charcot neuroarthropathy. Diabetic Foot J. 2011;14:163-70.

53. Armstrong DG, Lavery LA, Kimbriel HR, Nixon BP, Boulton AJ. Activity patterns of patients with diabetic foot ulceration: patients with active ulceration may not adhere to a standard pressure off-loading regimen. Diabetes Care. 2003;26(9):2595-7. https://doi.org/10.2337/diacare.26.9.2595.

\section{Publisher's Note}

Springer Nature remains neutral with regard to jurisdictional claims in published maps and institutional affiliations.

Ready to submit your research? Choose BMC and benefit from:

- fast, convenient online submission

- thorough peer review by experienced researchers in your field

- rapid publication on acceptance

- support for research data, including large and complex data types

- gold Open Access which fosters wider collaboration and increased citations

- maximum visibility for your research: over $100 \mathrm{M}$ website views per year

At BMC, research is always in progress.

Learn more biomedcentral.com/submissions 